\title{
Sentando las bases para una arqueología digital en Argentina. El rol de las infraestructuras digitales para la investigación
}

\author{
Andrés D. Izeta, Isabel Prado y Roxana Cattáneo \\ Recibido 16 de octubre 2020. Aceptado 30 de diciembre 2020
}

\begin{abstract}
RESUMEN
En el marco de las políticas públicas relacionadas con el desarrollo de la ciencia y técnica en la Argentina, es cada vez más evidente una orientación dirigida a la implementación de un modelo de ciencia abierta basado en la potencialidad ofrecida por los medios digitales. La arqueología no ha sido ajena a esto $y$, consciente o inconscientemente, se ha volcado hacia una práctica mediada por "lo digital". Para este modelo de ciencia, la accesibilidad a los datos primarios y la construcción de infraestructuras digitales para la investigación son prioritarias. Siguiendo esta idea, se implementó el Repositorio Digital Institucional Suquía (IDACOR, Universidad Nacional de Córdoba-CONICET), centrado en datos arqueológicos. En esta infraestructura digital se incluyen diversos tipos de información, que comparten una característica común: su difícil acceso, tanto físico como virtual, en su formato original. Bases de datos, informes, imágenes de excavaciones, de objetos y colecciones arqueológicas, son algunas de las clases de archivos contenidos en el repositorio. Este nuevo tipo de infraestructura se propone como un elemento de cambio en cómo se piensa y realiza la práctica arqueológica, ya que permite el uso y reúso de datos generados por financiamiento público, tanto para la investigación arqueológica, la gestión del patrimonio y la divulgación científica, así como para interesados en la temática.
\end{abstract}

Palabras clave: Infraestructura digital para la investigación; Repositorio digital; Arqueología digital; Acceso abierto; Ciencia abierta.

\section{Laying the foundation for a digital archaeology in Argentina: The role of e-research infrastructures}

\begin{abstract}
In Argentina, public policies related to scientific and technological development foster an open science model that is based on the potential offered by digital media. Archaeological practice, mainly supported by public funding, has accordingly turned towards a digitally-mediated practice by. For this model of science, accessibility to primary data and to e-research infrastructures is a priority. To this end, the Suquía Institutional Digital Repository (IDACOR, Universidad Nacional de Córdoba-CONICET), focused on the archiving of archaeological data, was implemented. This e-research infrastructure includes various types of information that share a common characteristic: low accessibility, both physical and virtual, in its original format. Databases, reports, images of excavations, archaeological objects and collections are just a few of

\footnotetext{
Andrés D. Izeta. Instituto de Antropología de Córdoba (IDACOR), Consejo Nacional de Investigaciones Científicas y Técnicas (CONICET)-Universidad Nacional de Córdoba y Departamento de Antropología, Facultad de Filosofía y Humanidades, Universidad Nacional de Córdoba, Avenida Hipólito Yrigoyen 174 (5000), Córdoba, Argentina. E-mail: aizeta@ffyh.unc.edu.ar

Isabel Prado. IDACOR, CONICET-Universidad Nacional de Córdoba y Museo de Antropología, Facultad de Filosofía y Humanidades, Universidad Nacional de Córdoba, Avenida Hipólito Yrigoyen 174 (5000), Córdoba, Argentina. E-mail: isabelprado@ffyh.unc.edu.ar

Roxana Cattáneo. IDACOR, CONICET-Universidad Nacional de Córdoba y Departamento de Antropología, Facultad de Filosofía y Humanidades, Universidad Nacional de Córdoba, Avenida Hipólito Yrigoyen 174 (5000), Córdoba, Argentina. E-mail: rcattaneo@ffyh.unc.edu.ar
}

Intersecciones en Antropología 22(1), enero-junio: 97-109. 2021. ISSN-e 1850-373X

https://doi.org/10.37176/iea.22.1.2021.595

Facultad de Ciencias Sociales - UNICEN - Argentina 
the file types that can be found in the repository. This new infrastructure is proposed as a game-changer in how archaeological practice is thought of and carried out, since it allows the use and reuse of data generated by public funding for archaeological research, heritage management, and scientific knowledge dissemination.

Keywords: e-Research infrastructure; Digital repository; Digital archaeology; Open access; Open science.

\section{INTRODUCCIÓN}

La práctica arqueológica supone, entre otras muchas cosas, la aplicación de estrategias diversas con el fin de interpretar aspectos relacionados con el desarrollo de individuos y poblaciones a lo largo del tiempo. Esta definición muy general de lo que implica hacer arqueología se encuentra atravesada por un sinnúmero de decisiones que son tomadas por los arqueólogos profesionales de manera individual y por grupos de investigación; en ambos casos mediadas por el contexto general de políticas científicas, social y temporalmente situadas. Esto ha dado como resultado la generación de muy distinta información relacionada con las diversas etapas de la investigación científica, la que en general culmina con una publicación científica como producto final (i.e., libros o capítulos de libros, artículos en revistas académicas). Sin embargo, si pensamos en el ciclo normal de un proyecto de investigación, existen etapas de las que no queda registro, o bien este último se convierte en lo que se ha dado en conocer como "literatura gris" (Falkingham, 2005; Evans, 2015), a saber, reportes, imágenes, planillas y todo otro tipo de documento u objeto en cualquier tipo de soporte físico o electrónico que no se encuentran publicados.

Históricamente, el modo de comunicar los avances de las investigaciones ha sido a través de los canales formales citados más arriba. Lentamente, los documentos (físicos) de los investigadores se han ido integrando, en los últimos años, a archivos institucionales, como es el caso del Museo de Antropología (Universidad Nacional de Córdoba), que se ha visto beneficiado por la donación de fondos documentales de investigadores como los de Jorge von Hauenschild y Aníbal Montes, depositados en el Archivo del Museo de Antropología de la UNC (Izeta, Mateo y Lencinas, 2013).

Aunque este caso no agota la cantidad de fondos documentales o colecciones digitales disponibles en la Argentina, sí es uno de los pocos en que se tiene acceso a otro tipo de producción más "cruda". En estas colecciones se pueden observar, también, los cambios en las formas de entender los problemas arqueológicos a medida que las investigaciones avanzan, así como los contextos políticos de producción en los que estas se desarrollan.

Sin embargo, entrado el siglo XXI, nos debemos preguntar qué sucede con los datos más modernos, actuales, que en su gran mayoría se generan directamente en formato digital y que, por ello, acompañan a los investigadores en computadoras personales, medios externos o en "la nube". Estos, sin duda, son más susceptibles a desaparecer por cuestiones fortuitas (aunque los documentos físicos también) o más comúnmente por la obsolescencia de equipamientos y de programas informáticos, que son reemplazados o abandonados y que ya no pueden ser utilizados (Izeta y Cattáneo, 2019).

Es por lo anterior que, desde comienzos de los años 2000, distintos actores interesados en la preservación de datos de interés científico implementaron iniciativas con el fin de concientizar a los investigadores sobre su importancia. En este sentido, el Sistema Nacional de Repositorios Digitales - MinCyT (Bongiovani y Nakano, 2011) y la Plataforma Interactiva de Investigación para las Ciencias Sociales PLIICS-CONICET (Leff y Pluss, 2015) han impulsado, a partir del apoyo a diversos proyectos, el desarrollo de distintas capacidades a nivel individual e institucional relacionados con la creación, uso, almacenamiento, preservación y difusión de datos digitales generados por proyectos arqueológicos (Izeta y Cattáneo, 2019).

Acompañando los procesos mencionados más arriba, se suma en el año 2013 la promulgación de la Ley $N^{\circ}$ 26.899/13 (Repositorios Digitales Institucionales de Acceso Abierto) que, en su artículo 1, expresa:

Los organismos e instituciones públicas que componen el Sistema Nacional de Ciencia, Tecnología e Innovación, [...] , y que reciben financiamiento del Estado nacional, deberán desarrollar repositorios digitales institucionales de acceso abierto, propios o compartidos, en los que se depositará la producción científico-tecnológica resultante del trabajo, formación y/o proyectos, financiados total o parcialmente con fondos públicos, de sus investigadores, 
tecnólogos, docentes, becarios de posdoctorado y estudiantes de maestría y doctorado.

Esta ley nacional, y su decreto reglamentario: Resolución 753 - E/2016, acompaña un proceso institucional de desarrollo de infraestructuras digitales por parte de universidades y organismos de CyT, en muchos casos como resultado de implementaciones surgidas de decisiones propias de las organizaciones.

Este contexto favorable, aunque incipiente en el campo de la arqueología, ha sentado las bases para que, desde el Instituto de Antropología de Córdoba (IDACOR), se creara la primera infraestructura digital dedicada a la preservación y diseminación de datos (de todo tipo) originados desde la práctica arqueológica.

En este trabajo presentaremos las características generales y la potencialidad que ofrece para desarrollar una nueva práctica que se da en Ilamar arqueología digital (Costopoulos, 2016; Izeta y Cattáneo, 2019).

\section{LAS INFRAESTRUCTURAS DIGITALES PARA LA INVESTIGACIÓN}

Es conocido que la práctica arqueológica moderna se funda en el uso de infraestructuras físicas que han ido desarrollándose a lo largo del tiempo, tales como las bibliotecas, los archivos y los museos (Anderson, 2013). Acordamos que estas infraestructuras preexistían y que, en los últimos años, han comenzado a migrar hacia "lo digital", lo que incluye no solo la digitalización de los recursos (por ejemplo, libros, documentos, imágenes o modelos 3D de objetos arqueológicos), sino también de los procesos. Por ejemplo, la resolución de los modos de recuperación de la información en contextos digitales o la necesidad de estandarizar esquemas de metadatos o, por último, los modos en que diferentes partes de un sistema van a interoperar.

La digitalización y la conversión de estas estructuras físicas en algo que pensamos como "lo digital" produce un primer cambio en la relación entre el investigador y su objeto de estudio, ya que en muchos casos ahora solo podemos acceder por medios remotos a información que antes era recuperada de un modo presencial y concreto. Entonces, ¿cómo entendemos a estas infraestructuras digitales en contraposición con las infraestructuras físicas? Aquí, antes de avanzar en la respuesta a esa pregunta, debemos aclarar que ambas infraestructuras son físicas, pero, en la práctica, lo que cambia es la forma de interactuar del investigador con cada una. Es decir, para las infraestructuras digitales lo que va a cambiar es el modo de acceso a los recursos, ya que al estar mediados por "lo digital", entendido en este caso como Internet (Boellstorff, 2012), se hará de un modo remoto. Al contrario de las maneras tradicionales de acceder a los datos, aquí no se necesita ir al centro de cómputos para recuperar o acceder a la información.

Entonces, una infraestructura digital para la investigación "denota el conjunto de la información, la experiencia, los estándares, políticas, herramientas y servicios que son compartidos ampliamente por las comunidades de investigación, pero que se desarrollan para propósitos académicos específicos" (Anderson, 2013, p. 8, traducción de los autores del original en inglés). Las infraestructuras pueden manifestarse ya sea por una implementación en "un lugar concreto (de un recurso particular)," o "pueden estar distribuidas (en una red de recursos)" (Anderson, 2013, p. 8, traducción de los autores del original en inglés). En este trabajo presentaremos una infraestructura digital para la investigación del primer tipo, que puede definirse como un repositorio digital y temático. Ejemplos del segundo tipo pueden verse en Meghini et al. (2017).

Pero ¿qué es un repositorio digital y temático? Podemos definir a un repositorio como un espacio (físico o virtual), donde guardamos objetos de diversos tipos y en diferentes soportes (Heery y Anderson, 2005). Sin embargo, este espacio debe cumplir una norma y esta es que todo lo que se albergue allí tiene que ser pasible de ser encontrado. De hecho, es uno de los conceptos clave dentro de los principios denominados FAIR (por las siglas en inglés de findable, accesible, interoperable y reusable; esto es, hallable, accesible, interoperable -entre sistemas informáticos-, reusable -para nuevas investigaciones-) (Wilkinson et al., 2016). Como ya se ha dicho, en el mundo físico podemos pensar a las reservas patrimoniales de los museos, a las bibliotecas o a los archivos, como distintos tipos de repositorios. Esto mismo sucede con los del mundo virtual. Por ello, y a los fines de preservar objetos digitales, es que se han desarrollado diversos softwares que permiten agregar información acerca de objetos digitales, del mismo modo en que una biblioteca, museo o archivo lo hace con sus objetos físicos. La posibilidad de un manejo controlado de los objetos digitales, y de poder compartir 
esto a través de Internet, es una característica que hace muy deseable la conformación de este tipo de infraestructuras virtuales.

Si trabajamos desde conceptos tales como el acceso abierto o la ciencia abierta (Budapest Open Access Initiative -BOAl-, 2001), compartir y poner a disposición datos científicos es primordial (Willinsky, 2005). Por ello, desde momentos muy tempranos se crearon repositorios dedicados a alguna de las ramas de la ciencia. Estos tomaron dos caminos: por un lado, el de especializarse en alguna temática en particular $y$, por el otro, el de constituirse en repositorios generales donde diversas materias pueden ser encontradas en el mismo espacio virtual. Entonces aquí tenemos otro de los conceptos clave, y es el de repositorio temático. En algún aspecto, este tipo de espacios virtuales Ilegaron para apoyar a los investigadores en el acceso a algunos tipos de información que eran muy difíciles de conseguir. Asimismo, a partir de este tipo de iniciativas comenzó a popularizarse el uso y reúso de datos con fines académicos (Kansa, 2015; Wylie, 2016). Sin embargo, debe decirse que el público en general también comenzó a relacionarse con estos espacios y a interactuar con datos científicos en proyectos de ciencia ciudadana (Fressoli, Arza y Del Castillo, 2016).

Los repositorios digitales pueden ser discriminados según su pertenencia a alguna institución o a un particular. En nuestro caso, nos focalizamos en los repositorios digitales institucionales. El cosechador SIUBDU ${ }^{1}$ del Sistema de Información Universitaria argentino (SIU), dependiente del Consejo Interuniversitario Nacional, registra un total de 56 repositorios digitales institucionales que disponen, en conjunto, de unos 389.603 objetos digitales en acceso abierto. Estos corresponden mayoritariamente a instalaciones desarrolladas en universidades nacionales, aunque también se agregan repositorios de otros organismos nacionales. Dos directorios internacionales, $\operatorname{ROAR}^{2}$ y Open DOAR, ${ }^{3}$ listan 66 y 70 repositorios para la Argentina, respectivamente.

De los 70 repositorios citados por Open DOAR, tomaremos dos ejemplos que son los que de algún modo han afectado la implementación del Repositorio Suquía, ya que el IDACOR, lugar donde se aloja, pertenece a dos organizaciones: la Universidad Nacional de Córdoba (UNC) y el Consejo Nacional de Investigaciones Científicas y Técnicas (CONICET). Ambos espacios poseen, hoy en día, sus repositorios institucionales, en los cuales mayormente se pueden hallar los resultados de investigaciones científicas o académicas. En el repositorio institucional de la UNC se pueden encontrar distintos tipos de obras, tales como tesis, libros, folletos, artículos académicos, manuscritos, etc. Por otro lado, el repositorio institucional del CONICET presenta solo los resultados de investigaciones científicas en formato de libros, capítulos de libros y artículos en revistas científicas, entre otros.

\section{CÓMO SURGE EL REPOSITORIO SUQUÍA}

En el año 2009, el CONICET conformó un grupo interdisciplinario preocupado por la preservación de datos científicos obtenidos mediante financiamiento del Estado. Dentro de este contexto, se gestó un plan piloto denominado Plataforma Interactiva de Investigación para las Ciencias Sociales (PLIICS). Esta iniciativa tuvo como objetivo la preservación, compilación e integración de datos para su uso en las ciencias sociales y humanidades (Leff y Pluss, 2015; Izeta y Cattáneo, 2019). En un primer momento, fue pensado como un espacio que permitiera la recolección de datos generados por investigadores y becarios del CONICET. Esto se propició a los fines de rescatar mucha de la información que, indefectiblemente, se estaba perdiendo día tras día por diversos motivos. El principal de ellos es el desconocimiento de los modos de preservación de los objetos físicos y digitales, que se deriva de la falta de un diseño estratégico de gestión de estos. Es decir, los organismos que financian proyectos de ciencia y técnica no habían tenido en cuenta un plan de manejo de datos.

Entre los años 2010 y 2013, en el marco de PLIICS, se realizaron diversas reuniones entre antropólogos, lingüistas, arqueólogos, historiadores, sociólogos, geógrafos, archivólogos y bibliotecarios, con el fin de discutir el uso de softwares, esquemas de metadatos y normas de buenas prácticas en la digitalización de los muy distintos tipos de datos producidos por investigadores de estas disciplinas. Al final de este periodo, se promulgó la ley sobre Repositorios Digitales Institucionales de Acceso Abierto. Como ya se dijo, esta ley obliga por primera vez a los investigadores que realicen trabajos con financiamiento del Estado a depositar las versiones de su trabajo (generalmente postprint, dependiendo de los derechos que retengan 
las instituciones, personas o las editoriales) y de sus datos primarios, en repositorios digitales institucionales.

Situados en esta dinámica, se identificó la necesidad de construir un repositorio institucional que fuera digital y temático, es decir, dirigido a la curaduría, preservación y diseminación de datos originados en la investigación arqueológica.

Una primera instancia de conformación de este repositorio se desarrolló sobre la base de la digitalización de datos primarios que se encontraban en soportes y formatos analógicos. Los problemas que se intentaban resolver mediante este proceso se relacionaban con enfrentar el desafío de la preservación de los conjuntos documentales, tanto institucionales producto de las actividades de gestión actual y del pasado, como aquellos que acompañan a los objetos arqueológicos. En una segunda instancia, se intentó revalorizar la información y datos que ofrecen documentos y colecciones de objetos antropológicos.

\section{ESTANDARIZACIÓN Y NORMAS}

La naturaleza de los datos arqueológicos es variable y se relaciona con las preguntas que intentamos responder desde esta aproximación. Esto genera un amplio abanico de problemáticas que, por ejemplo, pueden ir desde cuestiones más cualitativas -como estudios basados en conflictos sociales actuales, en cuestiones patrimoniales, legales y éticas dentro de la disciplina-, hasta datos generados en marcos de investigación cientificistas. Esta heterogeneidad se manifiesta en la caracterización de los datos arqueológicos definida por el acrónimo MEAN (que desde el inglés puede traducirse como "mezquino"), ya que son Misceláneos, Excepcionales, Arbitrarios e Inconformistas (Nonconformist) (Huvila, 2017). En otros términos, los datos arqueológicos pueden generarse a partir de protocolos consensuados por la comunidad de práctica o no. Quizás es esta última definición la que describe el estado de situación de los datos arqueológicos generados, hasta el momento, por un gran número de profesionales de la arqueología a escala global. Esta situación se debe, en gran parte, a la escasa estandarización de los protocolos de investigación y a la tradición de no compartir datos, salvo hacia el interior de los mismos equipos de investigación. Por supuesto, entendemos esto último como una generalización de la práctica, pero llegados aquí, es necesario reflexionar acerca de cuántos de nuestros datos o de los procesos que Ilevan a crearlos son explicitados o publicados para su análisis, uso y reúso por parte de la comunidad arqueológica.

Esta situación nos plantea un problema al momento de integrar estos datos diversos en plataformas o infraestructuras para la investigación. Por ello, cobra importancia el consenso entre los diversos actores que se integran en estas estructuras (arqueólogos, informáticos, profesionales de las ciencias de la información, etc.) en cuanto a la normalización y estandarización, no solo de los datos, sino también de aquella información que debe acompañarlos, como los metadatos y los paradatos. En este trabajo acordamos con Couper (2000) en las definiciones de estos conceptos. En el primer caso, nos referimos a aquella información que describe a los datos, en tanto que, en el segundo, hacemos referencia a los datos auxiliares que definen a los procesos involucrados en la recolección de los datos. Como resume Huvila (2012, p. 98), "el término connota información sobre los procesos a través de los cuales las personas han comprendido e interpretado los 'objetos de datos', incluidos los artefactos, estructuras, entornos y diferentes formas de datos relevantes del patrimonio cultural" (traducción de los autores a partir del original en inglés).

Como dijimos en otros trabajos (Izeta y Cattáneo, 2019; Izeta y Aguilar, 2020), es importante ser reflexivos a la hora de obtener datos que puedan ser compartidos. A este respecto, siguiendo a Richards (2009), debemos tener en cuenta al menos tres aspectos que llevan a una correcta estandarización. Estos son: a) los estándares técnicos, i.e., el hardware y software ya utilizados o los nuevos a ser empleados; b) los de contenido, i.e., los sistemas de registro de datos; c) los de metadatos, i.e., la documentación de datos en formatos que permitan la interoperabilidad entre esquemas y sistemas. A lo planteado por Richards, debemos agregar los de paradatos.

Dado que la infraestructura digital debe cumplir con estándares (técnicos, de metadatos, paradatos, etc.) que permitan lo anterior y que, desde un principio, fue pensada como un instrumento abocado a cumplir con los preceptos de la ciencia abierta, es que se determinó el uso de softwares de código abierto que poseen comunidades de desarrollo amplias y activas, y no programas cerrados, diseñados a medida. Uno de estos paquetes, DSpace, permite 
el uso de esquemas de metadatos como Dublin Core, que es mapeable con ISAD-g, utilizado en archivística, y MARC21, utilizado en el mundo de las bibliotecas.

En definitiva, la accesibilidad a los datos primarios se torna de fundamental importancia. En este sentido, y siguiendo el trayecto histórico que recién presentamos, disponer de medios adecuados se convierte en indispensable. Por ello, en el año 2016, antes de la reglamentación de la ley nacional se creó, en el marco del IDACOR-Museo de Antropología, el Repositorio Digital Institucional centrado en la temática arqueológica denominado Suquía. ${ }^{4}$ Aunque hemos planteado que la naturaleza de los datos arqueológicos es "mezquina", es decir, que nos ofrecen menos información que la que realmente deberíamos conocer, este repositorio se construyó siguiendo los principios FAIR (Wilkinson et al., 2016). Sobre esta base, se optó por una serie de atributos del repositorio, como el uso de un esquema de metadatos universal (Dublin Core), un software libre con una comunidad de soporte activa (DSpace) y que cumple con los requisitos que exigen las leyes nacionales en cuanto a depósito de datos primarios.

\section{Metadatos y paradatos}

Como definiéramos más arriba, los metadatos componen el conjunto de información que permite una descripción del dato. En general, los distintos esquemas se centran en información que permite recuperar, por ejemplo, el nombre de un autor, el título, descripción, temas o palabras clave de una obra, o en definitiva, de un objeto digital. Uno de los esquemas más populares es Dublin Core, un modelo de metadatos desarrollado y mantenido por la Dublin Core Metadata Initiative (DCMI, 2020). Este esquema presenta dos niveles. El primero, más básico (el modelo simple), se compone de 15 elementos, en tanto que el segundo (cualificado) es una extensión de aquel que permite que los 15 elementos previos sean más restrictivos. DCMI ha sido testeado desde el año 1995 y se ha convertido en norma (RFC 5791 [2010], Z39-85-2012, e ISO 15836-1:2017) para la recuperación de objetos digitales con presencia en Internet.

Para el caso de los paradatos de datos arqueológicos, la guía más comprehensiva desarrollada corresponde al Archaeology Data Service / Digital Antiquity Guía de Buenas Prácticas. ${ }^{5}$

\section{Vocabularios controlados}

Definir los esquemas de metadatos y paradatos es un primer paso que debe seguirse para la elección adecuada de vocabularios controlados. Es decir, teniendo los elementos ya seleccionados (e.g., los de Dublin Core simple), debemos saber qué ingresar en cada uno de ellos. Quien haya completado alguna vez una base de datos o un formulario on-line, habrá encontrado dificultades cuando el contenido de los campos no se encuentra estandarizado. Caracteres especiales como los acentos, errores de tipeo o la inclusión de mayúsculas o minúsculas son ejemplos de los errores más comunes en la carga. Sin embargo, existe otro tipo de problema que se relaciona con las definiciones de los términos que suelen estar sujetos a los marcos teórico-metodológicos en los que se generaron y a los usos y costumbres de las comunidades de práctica. Por ello, desde hace años se han establecido diversos nomencladores o "listados de autoridades" que permiten no solo el uso de términos estandarizados, sino también avanzar en cuestiones no contempladas al momento de la investigación arqueológica. Una de ellas es la posibilidad de ampliar la diseminación del conocimiento a partir de la capacidad de permitir el multilingüismo que poseen algunos vocabularios controlados. Es decir, al ingresar un término en un determinado idioma, se activa automáticamente su traducción a otros distintos.

Ejemplos de los vocabularios controlados mayormente utilizados en las ciencias sociales y humanidades son el Tesauro de Arte y Arquitectura, ${ }^{6}$ del Getty Research Institute, y Wikidata, ${ }^{7}$ de Wikimedia. En general, las bibliotecas nacionales suelen poseer sus propios vocabularios controlados o listado de autoridades, que ayudan a la catalogación de los objetos alojados en estas instituciones.

\section{PeriodO, nomenclador de periodos históricos y arqueológicos}

Una de las particularidades de la arqueología es el uso de la dimensión temporal. Aunque no es exclusiva de este tipo de estudios, a lo largo de la evolución de la disciplina se han generado modelos explicativos del desarrollo de las poblaciones humanas sobre la base de constructos teóricos tales como etapas y períodos (Rabinowitz et al., 2016; Aguilar, 2019; Izeta y Aguilar, 2020). Basándose en la diversidad de periodificaciones a escala global, se propuso su sistematización a partir del concepto de 
nanopublicación (Golden y Shaw, 2015), lo que ha producido, a la fecha, 6423 periodos. Esto permite nuevamente ubicar, en escala global, los procesos locales y, a través de la característica multilingüística de la base, hacer los datos accesibles a una mayor proporción de posibles usuarios.

\section{Nomencladores geográficos o gaceteros}

Existen nomencladores que agrupan diversos tipos de datos geográficos a partir de sus denominaciones. El Getty Thesaurus of Geographic Names, ${ }^{8}$ del Getty Research Institute, es recomendado por el Sistema Nacional de Repositorios Digitales en sus directrices (Sistema Nacional de Repositorios Digitales. Ministerio de Ciencia, Tecnología e Innovación Productiva, 2015). Complementariamente a este, se encuentra disponible en el Portal Nacional de Datos Abiertos el "Listado de los asentamientos humanos (localidad censal o paraje, sitio edificado), basado en la Base de Asentamientos Humanos de la República Argentina (BAHRA)" ${ }^{9}$

\section{EL REPOSITORIO}

Suquía se encuentra en una instalación del software DSpace. Este se presenta como solución para la implementación de repositorios, bibliotecas digitales, archivos de documentación electrónica, etc. Fue originalmente diseñado bajo el concepto de código abierto, lo que permite la expansión y mejora de los servicios ofrecidos, así como la posibilidad de adaptarlo a situaciones particulares. Es multiplataforma, por lo que puede instalarse en diversos sistemas operativos. Es uno de los softwares más populares en el mundo. Según el Open Directory of Open Access Repositories, el 39\% ( $n=2161)$ de los repositorios registrados a nivel mundial utilizan DSpace. En Argentina, el 54\% ( $n=38)$ de las instalaciones corren bajo alguna de las versiones de este programa. Esto garantiza la correcta interoperabilidad entre los sistemas (característica solicitada por FAIR y las directrices del SNRD) y la posibilidad de realizar cosechas de información entre repositorios.

Suquía se estructura siguiendo los niveles de agregación propuestos por el software. Estos son tres: Comunidad, Subcomunidad y Colección. Los objetos digitales se integran en alguno de estos niveles.

La unidad de información se denomina ítem, y puede constar de un objeto digital o de varios, según contengan material complementario o paradata. Esto se acompaña del conjunto de metadatos que describen al o a los objetos digitales. Cada ítem posee un marcador persistente, expresado dentro del Sistema Handle. Por ello, si un ítem debe moverse de una colección a otra no se pierde su trazabilidad. Esto permite un sistema flexible de ubicación de los ítems en la estructura y la posibilidad de reestructurar el repositorio cada vez que sea necesario.

Cada colección, e incluso cada ítem, puede ser curado y administrado por distintos roles dentro del sistema. Suquía cuenta con administradores generales para cuestiones que se relacionan con el mantenimiento de la implementación. Por otro lado, las colecciones originadas en el repositorio tienen asignados administradores de la colección, usuarios autorizados al envío de ítems, curadores de los datos y publicadores. Eso garantiza un flujo de trabajo de acuerdo con el cual cada ítem ingresado al sistema es sometido a varias instancias de revisión y enriquecimiento de la información, a partir de su vinculación con metadatos y paradatos y, finalmente su archivado y publicación.

El sistema cuenta con distintos niveles de acceso a la información. En principio, cualquier persona con acceso a Internet puede interactuar con el catálogo en línea. Allí se despliega la información agrupada en los niveles propios de DSpace y puede hacerse una exploración, siguiendo la estructuración a partir de las descripciones de cada comunidad, subcomunidad o colección. El sistema también cuenta con un motor de búsqueda incorporado, lo que permite realizar consultas a partir de una palabra clave o de una cadena de palabras. Esto se realiza sobre los metadatos asociados con cada ítem y sobre el texto del documento, si estuviera disponible.

Los objetos pueden someterse a una escala de seguridad, que parte desde el embargo total del ítem por un tiempo determinado, hasta el acceso libre. Esto permite el tratamiento de ítems que contengan datos sensibles. Por ello, los ítems alojados en Suquía pueden ser inaccesibles para los usuarios externos, accesibles solo a los metadatos o totalmente accesibles. También puede otorgarse permiso de acceso a ítems restringidos a usuarios individuales.

En la Figura 1 se sintetiza el flujo de trabajo para la publicación y resguardo o solo resguardo, en el caso de solicitar embargo en Suquía. También las formas posibles en que los datos pueden integrarse a 

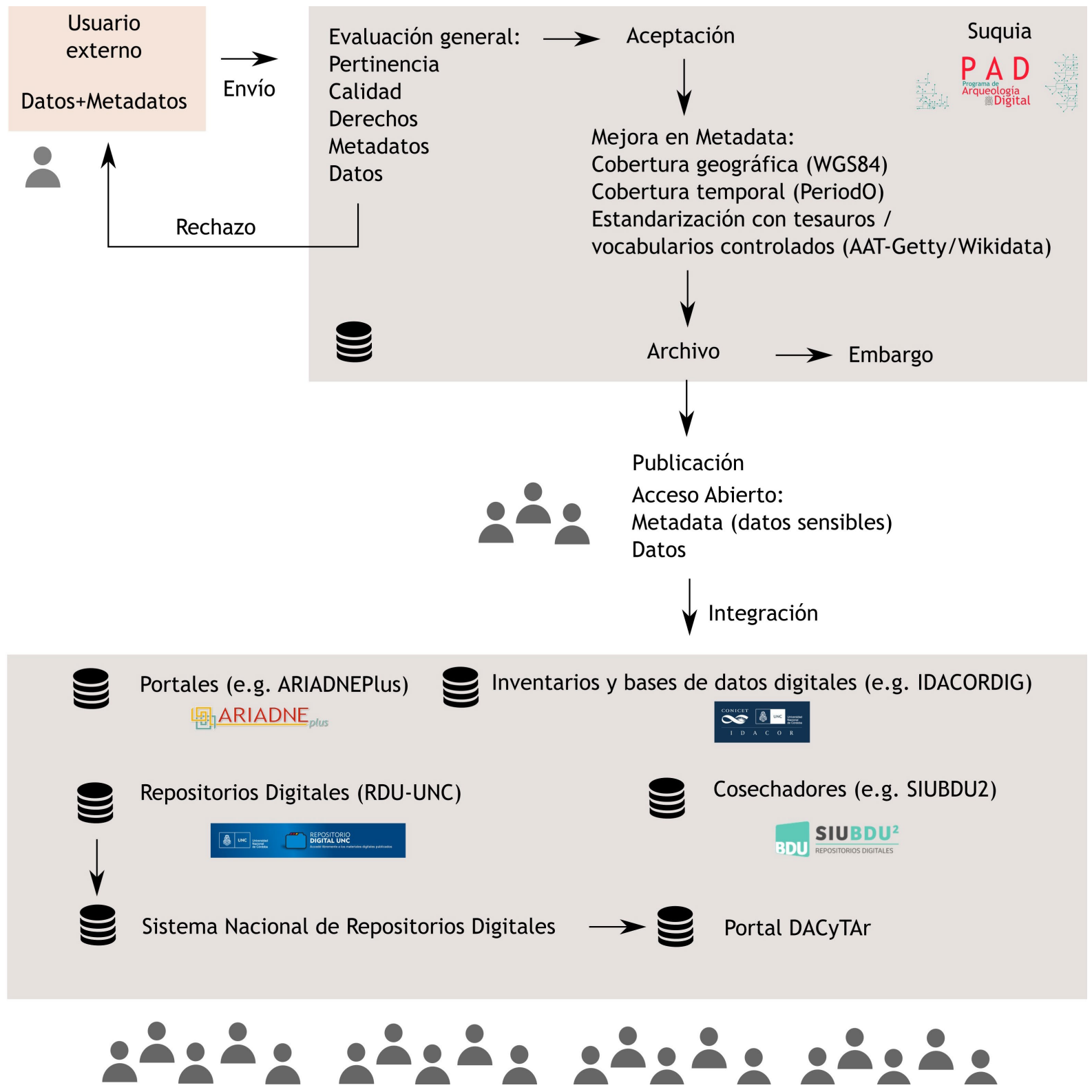

Figura 1. Flujo de trabajo del Repositorio Suquía. Modificado de https://wiki.lyrasis.org/display/DSDOC5x/Functional+Overview

otras plataformas (i.e., SIU-BDU2, Sistema Nacional de Repositorios Digitales, o el portal DACyTAr, que cosecha sus datos desde este sistema nacional).

Un usuario externo solicita autorización para el envío de un ítem. Este es recibido por los administradores $y$, posteriormente, derivado al administrador de la colección, quien realiza una evaluación del ítem teniendo en cuenta diversos aspectos. En principio, la pertinencia temática del objeto digital. Una vez establecida esta, se evalúa la calidad digital del objeto (formato, integridad, etc.). En este punto, si el archivo puede convertirse a un formato estable, se realiza esa tarea. Por ejemplo, a un archivo de MSWord (*.docx) que presenta solo texto, se lo transforma al formato *.txt o *.html; o a un archivo de MSExcel (*.xIsx), y si no posee fórmulas o celdas /hojas vinculadas, se lo convierte en un archivo *.csv. El ítem presentará, en estos casos, ambos archivos: el original y el convertido. Por último, se realiza una evaluación de los metadatos introducidos por el usuario externo y los derechos que posee para su publicación en el repositorio. Si algunas de estas variables no se cumplen satisfactoriamente, el envío se rechaza. Esta etapa funciona como un sistema de publicación tradicional, en el cual las revisiones son realizadas por personal especializado abocado a las tareas de curación de datos. En un futuro, puede integrarse al proceso la evaluación externa que garantice la calidad de los objetos que se habrán de integrar al repositorio. 
Vale aclarar que los ítems pueden ser subidos individualmente, un proceso que es lento, con lo cual insume mucho tiempo, o bien pueden subirse en lote, lo que permite la incorporación de varios ítems a la vez de un modo más ágil. La incorporación de nuevos datos, sea cual sea el método de ingreso, es sometida a un enriquecimiento de información por medio de la estandarización de metadatos. En particular, trabajamos en el enriquecimiento de información relacionado con la cobertura geográfica (normalizando nombres de lugares mediante los nomencladores citados más arriba) y la cobertura temporal (usando PeriodO y otros datos como fechados absolutos).

El Repositorio Suquía posibilita a la comunidad acceder a diversos tipos de información que poseen, como común denominador, que son difíciles de obtener en su formato original. Bases de datos, informes, presentaciones en eventos científicos, imágenes de excavaciones, imágenes de colecciones arqueológicas, son solo algunos de los tipos de objetos contenidos en el repositorio. Dentro de estos se destacan algunas colecciones, por ejemplo: Reserva Patrimonial del Museo de Antropología IDACOR (colecciones del litoral, Patagonia, Córdoba y NOA, entre otras); Publicaciones del Instituto de Arqueología, Lingüística y Folklore y del Instituto de Antropología; y las de sitios o áreas arqueológicas trabajadas por proyectos vigentes (e.g., Alero Deodoro Roca, Parque Natural Ongamira 1).

Otro material disponible es lo que se denomina "literatura gris", como por ejemplo, informes de estudios de impacto arqueológico realizados en la ciudad de Córdoba. Por último, se encuentran disponibles algunas bases de datos, como la de fechados radiocarbónicos de Córdoba, o la Base de Sitios Arqueológicos de Córdoba, producto de la colaboración entre los equipos de investigación arqueológica de la Universidad Nacional de Córdoba y la Universidad Nacional de Río Cuarto.

A la fecha, se cuenta con más de tres mil objetos digitales disponibles bajo licencias Creative Commons (en general, la Licencia Creative Commons Atribución 4.0 Internacional, aunque dependiendo del objeto puede variar entre una licencia totalmente libre hasta la más restrictiva) para su uso y reúso, tanto para la investigación arqueológica como para interesados en la temática. Estos objetos han recibido, durante el periodo de funcionamiento del repositorio, 277.090 búsquedas, lo que implica una media de unas 190 búsquedas diarias desde el año 2016 hasta octubre de 2020.

Por último, se plantea una estrategia para la preservación digital que comprende dos tipos de acciones. Por un lado, la curación de los datos digitales que, además del enriquecimiento de metadatos y paradatos, incluya un plan de copias de seguridad de la información que es provisto por la Prosecretaría de Informática de la Universidad Nacional de Córdoba. Esto garantiza un tipo de preservación que tiene que ver con la integridad del dato digital. Por otro lado, aunque aún no ha sido necesaria su implementación, se ha diseñado una estrategia que permita, a futuro, mediante el uso de emuladores, la vigencia de datos que no puedan migrarse a formatos estándares estables (e.g., *.txt). Estos emuladores permiten crear el ecosistema digital en el cual se puedan reutilizar dichos datos, evitando de ese modo la obsolescencia y la pérdida de estos.

\section{COLECCIONES EN SUQUÍA: EJEMPLOS}

El Repositorio Suquía está compuesto en la actualidad por 19 comunidades divididas en 201 colecciones. A fines ilustrativos, presentaremos tres de estas comunidades y sus colecciones. La primera corresponde a la del ingeniero Aníbal Montes. La segunda, al equipo de investigación del Valle de Ongamira. Finalmente, la colección que reúne información sobre estudios de impacto arqueológicos en la ciudad de Córdoba. Esto nos permite ver los tipos documentales y de registro disponibles en Suquía. Algunas de ellas, de corte histórico, y otras más modernas, producto de la actividad arqueológica actual.

\section{Fondo Documental Aníbal Montes ${ }^{10}$}

El Fondo Documental Aníbal Montes fue conformado en el periodo 1939-1959, correspondiente con el trabajo de Aníbal Montes (militar, ingeniero y arqueólogo) en la provincia de Córdoba, quien registró y excavó sitios arqueológicos. De aquí surgen descripciones de excavaciones y de cultura material de sitios como Ayampitin, Ongamira, la Gruta de Candonga, el Cerro Colorado o Miramar, los que fueron y son sitios claves para interpretar la historia regional prehispánica (Laguens y Bonnin, 2009; Cattáneo, Izeta y Acosta, 2015). Esto hace que el fondo documental sea de interés para los 
investigadores interesados en esta temática (Izeta et al., 2013).

Esta colección se encontraba clasificada al momento de su recepción, en el año 2010, por lo cual solo fue intervenida para su conservación preventiva, catalogación y descripción de los documentos que la componen con el fin de elaborar un catálogo. El resultado de este proceso generó un total de 16.200 objetos digitales, los cuales fueron agrupados en 2000 archivos en PDF (Izeta et al., 2013).

El contenido de esta colección es variable. Se destacan algunas versiones de trabajos científicos (desde su manuscrito original hasta versiones comentadas de la obra publicada), cartografía y descripción de sitios arqueológicos. Esto último fue de vital importancia para la creación de la Base de Datos de Sitios Arqueológicos (BaDaCor) (Cattáneo et al., 2015) que fuera luego actualizada por Patrimonio del Gobierno de la Provincia de Córdoba. Esto sentó bases para el desarrollo de trabajos arqueológicos, como por ejemplo el efectuado en el área de Villa de Soto (Ochoa y Ferreira, 2019) o la creación de dos reservas arqueológicas provinciales (Quilpo y Guasapampa).

Toda la colección se encuentra publicada bajo una Licencia Creative Commons Atribución-No Comercial-Sin Derivadas 2.5 Argentina.

\section{Colección Ongamira $^{11}$}

Disponible en línea desde el año 2016. Se encuentra dividida en subcomunidades que integran diferente información, principalmente imágenes del proceso de excavación de sitios arqueológicos. Además, se integran modelos 3D (en formato *.ply) y registros de excavación, entre otros documentos. Otras subcomunidades corresponden a bibliografía generada en el marco de las actividades arqueológicas, divulgación científica y presentaciones en reuniones científicas. A esto se le suma la muestra museográfica del Museo Viajero y el diseño de la actividad didáctica Valijas Viajeras.

Con respecto a la Colección Ongamira, en 2017 se utilizó como parte del $1^{\circ}$ Seminario "Arqueología Digital" de la Licenciatura en Antropología de la Facultad de Filosofía y Humanidades (a cargo de Izeta y Cattáneo) para formar a alumnas y alumnos de grado en la temática de los repositorios.

Esta colección contiene unos 550 objetos digitales y se encuentra publicada bajo una Licencia
Creative Commons Atribución-No Comercial-Sin Derivadas 2.5 Argentina.

\section{Colección Estudios de Impacto Arqueológico $^{12}$}

Esta colección se compone de "literatura gris" y corresponde mayormente a informes elevados a dependencias gubernamentales (Dirección de Cultura y Patrimonios de la Municipalidad de Córdoba y Dirección de Patrimonio Cultural de la Provincia de Córdoba).

En ella se registran once sitios, representados por 308 objetos digitales. Cada sitio puede presentar informes parciales y finales de la actuación, imágenes de excavación o de objetos recuperados y modelos 3D. Está integrada con la plataforma IDACORDig, ${ }^{13}$ que permite visualizar la ubicación geográfica de cada sitio intervenido. Para uno de los sitios se encuentra disponible no solo el modelo 3D, sino también toda la serie fotográfica que sirvió de base para su construcción, lo cual permite la reproducción del proceso fotogramétrico.

\section{LA CONSTRUCCIÓN DE REDES. EL ENFOQUE DE LA ARQUEOLOGÍA DIGITAL}

La preservación digital y física es colaborativa. Preservar tiene que ver con una comunidad dinámica y diversa de trabajo, que ofrece conocimientos y se desarrolla en la práctica. Las redes y la colaboración han sido los cimientos de una respuesta compartida a un desafío global: el acceso abierto. Esto se ha puesto de manifiesto, hoy más que nunca, frente al reto que le imprimió al mundo y a las ciencias la pandemia y el aislamiento social, dado que trascendió los límites físicos e hizo evidente un hecho que se convirtió en familiar: la utilidad y necesidad de los repositorios institucionales, la conveniencia de contar con datos en los medios virtuales y la posibilidad de compartirlos entre grupos con intereses específicos. También, se hace evidente que no se puede preservar de manera individual. De aquí lo imperioso de este trabajo, la importancia de trazar redes y de conectarlas.

Para la arqueología, la construcción de redes no es una novedad, pero es fundamental en un enfoque digital. Si bien la disciplina arqueológica está atravesada por el uso de herramientas digitales, adoptar un enfoque digital en arqueología requiere de un conjunto de habilidades y conocimientos 
específicos, tales como la vinculación de bases de datos, el uso de estadística, el modelado 3D, la implementación de sistemas de información geográfica, entre otros. Esto propicia el intercambio de trabajo en entornos de acceso abierto y la visualización de la información por medio de nuevas tecnologías y medios. Asimismo, la construcción de redes, tanto nacionales como internacionales, aumenta la visibilidad y alcance del repositorio como consecuencia de los objetos a su resguardo, de la investigación arqueológica, la gestión del patrimonio y la divulgación científica.

\section{CONCLUSIONES}

Aquí intentamos introducir a un público amplio un aspecto de la arqueología que lentamente se ha ido filtrando en la práctica profesional, que es el uso de datos originados digitalmente y un creciente corpus de objetos digitalizados. Así como se ha discutido sobre la preservación de las colecciones arqueológicas generadas por proyectos de investigación, este trabajo tiene como fin comenzar la discusión acerca del ciclo de los datos digitales o digitalizados que se producen en el ámbito de la arqueología argentina. Además, intentamos presentar una propuesta metodológica enmarcada en lo que se ha definido, a nivel mundial, como arqueología digital, una aproximación que aún no ha sido discutida a nivel teórico en forma profunda en contextos globales, y aún menos, en la arqueología sudamericana (Izeta y Cattáneo, 2019). Sin embargo, creemos que esa discusión teórica es parte de algo más extenso, que puede ser un aporte a la cuestión teórica de la arqueología posicionados desde el sur global.

Por otro lado, las infraestructuras digitales se encuentran en pleno desarrollo y las implementaciones de nuevas instancias se van sucediendo con continuidad, tanto a nivel global como a nivel nacional, lo que debería garantizar la preservación digital a largo plazo de los ítems alojados en dichas estructuras digitales. Asimismo, entendemos que permitirán un incremento en el metaanálisis de la producción académica, así como se observa a nivel internacional (e.g., Kansa, 2015). Esto, de algún modo, promueve el reúso de información generada previamente y, con ello, una optimización de los recursos económicos volcados a la investigación científica, particularmente si esta está financiada con fondos públicos. Pensamos que esto sienta las bases para proponer una nueva forma de práctica, que creemos que será cada vez más popular entre las jóvenes generaciones de arqueólogos, más acostumbradas al uso de recursos digitales.

En definitiva, el Repositorio Suquía, como infraestructura digital, es una realidad, y se constituye como el primer repositorio digital institucional temático de acceso abierto de la Argentina y de Sudamérica. Por ello, los invitamos a que lo conozcan, lo usen y, si están interesados, integren sus datos para hacer de la arqueología argentina una pionera en la construcción de una ciencia abierta y colaborativa (para esto último, basta con crear una cuenta en el sistema, aunque se sugiere contactar a cualquiera de los autores del presente trabajo). En este sentido, un objetivo fundamental es propiciar una reflexión profunda acerca de las prácticas profesionales relacionadas con la preservación de los datos generados durante el ciclo de vida de los proyectos, para que estos perduren y puedan ser reutilizados bajo nuevos marcos teóricos y metodologías en el presente y en el futuro.

\section{Agradecimientos}

Queremos agradecer a quienes han acompañado el proceso de desarrollo e implementación de esta nueva línea temática en la arqueología argentina: Mirta Bonnin, Jorge Tezón, Laura Leff, Martín Oliver, Silvia Mateo, Alejandra Nardi, Tomás Cohen, Alexis Febre, José Bustos, Miguel Montes, Julián Mignino, Marcela Tintilay, Andrés Robledo, Bernarda Conte. A quienes diariamente contribuyen con el crecimiento del repositorio: Paloma Laguens, Eduardo Pautassi, Soledad Ochoa, Diego Carro.

Asimismo, a las instituciones de las que formamos parte, la UNC y el CONICET por su apoyo constante. Este trabajo forma parte del proyecto "ARIADNEplus" (H2020 Programme, contract no. H2020-INFRAIA-2018-1-823914)", el "Proyecto integral de investigación, preservación y transferencia del patrimonio del Instituto de Antropología de Córdoba, UNC-CONICET" Proyecto PUE $22920160100024 \mathrm{CO}$ y el Proyecto SPU-SECyT UNC 2020-32520200100030CB “Preservación y puesta en valor de colecciones científicas patrimonializadas en museos, bibliotecas y repositorios digitales abiertos".

Finalmente, queremos agradecer a los revisores anónimos por sus correcciones y sugerencias para mejorar el manuscrito original, aunque la 
responsabilidad por lo expresado es exclusiva de los autores.

\section{REFERENCIAS CITADAS}

Aguilar, L. H. (2019). Aproximaciones cronológicas en la arqueología cordobesa: Una evaluación crítica de los usos y prácticas en los últimos 140 años (Trabajo final de licenciatura). Facultad de Filosofía y Humanidades. Universidad Nacional de Córdoba. Córdoba, Argentina.

Anderson, S. (2013). What are Research Infrastructures? International Journal of Humanities and Arts Computing, 7(1-2), 4-23. https://doi.org/10.3366/ ijhac.2013.0078

BOAI (2001). Budapest Open Access Initiative. https:// www.budapestopenaccessinitiative.org/translations/ spanish-translation

Boellstorff, T. (2012). Rethinking Digital Anthropology. En H. A. Horst y D. Miller (Eds.), Digital Anthropology (pp. 39-60). Berg Publishers.

Bongiovani, P. y Nakano, S. (2011). Acceso abierto en Argentina: La experiencia de articulación y coordinación institucional de los repositorios digitales en ciencia y tecnología. E-colabora, 1(2), 163-179.

Cattáneo, R., Izeta, A. D., y Costa, T. (2015). El patrimonio arqueológico de los espacios rurales de la provincia de Córdoba. Museo de Antropología-IDACOR. https:// suquia.ffyh.unc.edu.ar/handle/suquia/526

Costopoulos, A. (2016). Digital Archeology Is Here (and Has Been for a While). Frontiers in Digital Humanities, 3, 4. https://doi.org/10.3389/fdigh.2016.00004

Couper, M. P. (2000). Usability Evaluation of ComputerAssisted Survey Instruments. Social Science Computer Review, 18(4), 384-396. https://doi. org/10.1177/089443930001800402

DCMI (2020). Dublin Core Metadata Initiative DCMI. https://www.dublincore.org/

Evans, T. N. L. (2015). A Reassessment of Archaeological Grey Literature: Semantics and paradoxes. Internet Archaeology, 40. https://doi.org/10.11141/ia.40.6

Falkingham, G. (2005). A whiter shade of grey: A new approach to archaeological grey literature using the XML version of the TEI Guidelines. Internet Archaeology, 17. http://dx.doi.org/10.11141/ia.17.5

Fressoli, M., Arza, V. y Del Castillo, M. (2016). The impact of citizen generated data in Argentina. https://doi. org/10.13140/RG.2.1.3285.4807

Golden, P., y Shaw, R. (2015). Period assertion as nanopublication. Semantics, Analytics, Visualisation: Enhancing Scholarly Data. Workshop Co-Located with the 24th International World Wide Web Conference, Florence, Italy. https://www.researchgate. net/publication/311488286_Period_Assertion_as_ Nanopublication_The_PeriodO_Period_Gazetteer

Heery, R. y Anderson, S. (2005). Digital repositories review. Joint Information Systems Committee.

Huvila, I. (2012). The Unbearable Complexity of Documenting Intellectual Processes: Paradata and Virtual Cultural Heritage Visualisation. Humanit, 12(1), 97-110.

Huvila, I. (2017). Being FAIR when archaeological information is MEAN: Miscellaneous, Exceptional, Arbitrary, Nonconformist. Centre for Digital Heritage 2017 conference, Leiden, Holanda. http://www. istohuvila.se/node/526

Izeta, A. D., y Aguilar, L. H. (2020). Estandarización de categorías temporales utilizadas en la arqueología del centro de Argentina en los últimos 140 años. Nuevos usos de viejos datos. MS.

Izeta, A. y Cattáneo, R. (2019). Archaeological digital repositories: Fostering networks from the Global South. En F. Nicolucci y J. Richards (Eds.), The Ariadne Impact (pp. 163-174). Archaeolingua.

Izeta, A., Mateo, S. y Lencinas, V. (2013). Digitalización del Fondo Documental Aníbal Montes (Museo de Antropología, FFyH, UNC): Práctica interdisciplinaria. En IV Encuentro de Museos Universitarios del Mercosur I Encuentro de Museos Universitarios Latinoamericanos y del Caribe. Museo Histórico UNL Universidad Nacional del Litoral.

Kansa, S. W. (2015). Using Linked Open Data to Improve Data Reuse in Zooarchaeology. Ethnobiology Letters, 6(2), 224-231. https://doi.org/10.14237/ ebl.6.2.2015.467

Laguens, A., y Bonnin, M. (2009). Sociedades Indígenas de las Sierras Centrales. Arqueología de Córdoba y San Luis, Argentina. Editorial Universitaria, Universidad Nacional de Córdoba.

Leff, L., y Pluss, R. (2015). Plataforma Interactiva de Investigación en Ciencias Sociales. En G. Río Riande, L. Cantamutto, y L. Striker (Eds.), I Jornadas Nacionales de Humanidades Digitales. Asociación Argentina de Humanidades Digitales (pp. 137-142). Editorial de la Facultad de Filosofía y Letras.

Meghini, C., Scopigno, R., Richards, J., Wright, H., Geser, G., Cuy, S.,... . y Vlachidis, A. (2017). ARIADNE: A Research Infrastructure for Archaeology. Journal on Computing and Cultural Heritage, 10(3), 18:1-18:27. https://doi.org/10.1145/3064527

Ochoa, S., y Ferreira, M. E. (2019). Relectura del 
Nomenclador cordobense de toponimia autóctona de Aníbal Montes. Correlaciones entre la documentación etnohistórica y la distribución de sitios arqueológicos pre-conquista del noroeste de Córdoba. Sociedades de Paisajes Áridos y Semiáridos, 13, 40-57. http://www2. hum.unrc.edu.ar/ojs/index.php/spas/article/view/856

Rabinowitz, A., Shaw, R., Buchanan, S., Golden, P., y Kansa, E. (2016). Making Sense of the Ways We Make Sense of the Past: The PeriodO Project. Bulletin of the Institute of Classical Studies, 59(2), 42-55. https://doi. org/10.1111/j.2041-5370.2016.12037.x

Richards, J. (2009). From anarchy to good practice: The evolution of standards in archaeological computing. Archeologia e Calcolatori, 20, 27-35. http://www. archcalc.cnr.it/indice/PDF20/3_Richards.pdf

Sistema Nacional de Repositorios Digitales. Ministerio de Ciencia, Tecnología e Innovación Productiva. (2015). Directrices para proveedores de contenido del Sistema Nacional de Repositorios Digitales. http:// repositoriosdigitales.mincyt.gob.ar/files/Directrices_ SNRD_2015.pdf

Wilkinson, M. D., Dumontier, M., Aalbersberg, Ij. J., Appleton, G., Axton, M., Baak, A., ... . y Mons, B. (2016). The FAIR Guiding Principles for scientific data management and stewardship. Scientific Data, 3, 160018. http://dx.doi.org/10.1038/sdata.2016.18

Willinsky, J. (2005). The unacknowledged convergence of open source, open access, and open science. First Monday, 10(8). https://doi.org/10.5210/fm.v10i8.1265

Wylie, A. (2016). How Archaeological Evidence Bites Back: Strategies for Putting Old Data to Work in New Ways. Science, Technology, y Human Values, 42(2), 203-225. https://doi.org/10.1177/0162243916671200

\section{NOTAS}

1.- http://cosechador.siu.edu.ar/bdu3/ consultado el 11 de septiembre de 2020.

2.- http://roar.eprints.org/ consultado el 5 de octubre de 2020 .

3.- https://v2.sherpa.ac.uk/view/repository_by_country/ Argentina.html consultado el 5 de octubre de 2020.

4.- https://suquia.ffyh.unc.edu.ar/

5.- https://guides.archaeologydataservice.ac.uk/g2gp/ UsingGuides consultado el 5 de octubre de 2020.

6.- https://www.getty.edu/research/tools/vocabularies/ aat/ o en español https://www.aatespanol.cl/ consultado el 5 de octubre de 2020.

7.- https://www.wikidata.org/wiki/ Wikidata:Introduction/es consultado el 5 de octubre de 2020 .

8.- https://www.getty.edu/research/tools/vocabularies/ tgn/index.html consultado el 5 de octubre de 2020.

9.- https://datos.gob.ar/dataset/jgm-servicio-normalizacion-datos-geograficos/archivo/jgm_8.7 consultado el 5 de octubre de 2020.

10.- https://suquia.ffyh.unc.edu.ar/handle/suquia/2419

11.- https://suquia.ffyh.unc.edu.ar/handle/suquia/2

12.- https://suquia.ffyh.unc.edu.ar/handle/suquia/32

13.- https://idacordig.unc.edu.ar/ 
